\title{
Datalogger Experimental Analysis Based on Arduino Mega 2560 on a 100 Wp Monocrystalline Solar Panel Using Perforated Plate
}

\author{
W. Adipradana ${ }^{1}$ A. Sofijan ${ }^{1, *}$ Rahmawati $^{1}$ I. Bizzy ${ }^{2}$ R. Sipahutar ${ }^{2}$ M. A. Fajri ${ }^{1}$ \\ ${ }^{1}$ Department of Electrical Engineering, Engineering Faculty, Sriwijaya University, Indonesia \\ ${ }^{2}$ Department of Mechanical Engineering, Engineering Faculty, Sriwijaya University, Indonesia \\ *Corresponding author. Email: a_sofijan@ft.unsri.ac.id
}

\begin{abstract}
This experiment was carried out to reduce excess heat in solar panels and increase the output power generated by the $100 \mathrm{Wp}$ monocrystalline solar panel by applying perforated aluminum plates as a Passive Cooling Technique on solar panels. The energy source used is $12 \mathrm{~W}$ halogen lamps as a substitute for solar energy and data collection is carried out with a solar panel rack height of $350 \mathrm{~mm}$. The resulting data will be recorded automatically by a datalogger based on Arduino Mega 2560 and stored on a Micro SD Card which is operated via a computer. The perforated aluminium plate used has the length of $1000 \mathrm{~mm}$, the width of $670 \mathrm{~mm}$, the thickness of $2 \mathrm{~mm}$, the hole diameter of $2.5 \mathrm{~mm}$ and the distance between the center points of the hole of $20 \mathrm{~mm}$. In this experimental research, the best results of PV panels equipped with perforated aluminium plate are the voltage of $13.25 \mathrm{~V}$, the current of $4.36 \mathrm{~A}$, the under temperature of $32.0^{\circ} \mathrm{C}$, and the output power of $57.77 \mathrm{~W}$.
\end{abstract}

Keywords: Data Logger, Monocrystalline, Passive Cooling, Perforated Aluminium Plate, Photovoltaic

\section{INTRODUCTION}

Indonesia is a country that is located on the equator. Therefore, the mainland of Indonesia is irradiated by the sun for approximately 12 hours a day or most of the year. Solar energy in Indonesia has an intensity between $0.6-0.7 \mathrm{~kW} / \mathrm{m} 2$. In sunny conditions, the surface of the earth receives $\pm 1000 \mathrm{~W}$ of solar energy/m2. Less than $30 \%$ is reflected back to the atmosphere, $47 \%$ is converted to heat, $23 \%$ is used for working circulation on the earth's surface, $0.25 \%$ is stored in wind, waves \& currents, and $0.025 \%$ is stored for photosynthesis in plants. The amount of potential solar energy obtained by the earth in just 1 hour is equivalent to the amount of energy used by the world in over a year. Abundant potential of solar energy, photovoltaic (PV) technology is needed to convert solar energy into DC electrical energy. The use of PV also supports energy conservation programs, namely increasing energy efficiency, reducing the use of fossil fuels, and increasing the provision of environmentally friendly and renewable energy sources [1].

The development of the PV industry is very fast. One of them is the use of technology to convert direct solar radiation into electrical energy by applying a silicon $\mathrm{p}-\mathrm{n}$ connection. This technology utilizes radiation from sunlight to be used without the need to convert it into heat which can generate theoretically high efficiency [2]. The results of previous studies show that the current panel increases dramatically during $10 \mathrm{am}$ to $1 \mathrm{pm}$ due to increased sun intensity but starts to fall above $1 \mathrm{pm}$ to $5 \mathrm{pm}$ due to decreased sun intensity. And it has been simulated that when the temperature of the PV panel increases, the output power of the PV panel decreases and its performance decreases. Meanwhile, due to weather conditions and ambient temperature the output power output may decrease. The results show that the presence of solar radiation falling on the surface of the PV panel affects the ambient temperature and the temperature of the PV panel. One of the most important is the temperature effect, when high temperature will produce low voltage or vice versa [3].

In order to overcome the effect of PV panel temperature on the output of increased electric current, a cooling system is needed. The PV panel was modified by installing a cooling device on the back of the panel in the form of a perforated aluminum plate. The advantage 
of using perforated aluminum plates as a cooling medium for PV panels is that they are practical, easy to manufacture, and do not require power due to free convection cooling. So that the plate surface is relatively lower temperature can dissipate heat on the surface of the PV panel, and the manufacture is simpler because it does not use transparent glass [4][5]. In research perforated plates were used in the drying process of agricultural products. For this reason, the authors took the initiative to conduct research in an effort to improve the efficiency and output power of solar panels through a study entitled "Datalogger Experimental Analysis Based on Arduino Mega 2560 on a $100 \mathrm{Wp}$ Monocrystalline Solar Panel Using Perforated Plate".

\section{PASSIVE COOLING TECHNIQUE}

Passive cooling techniques can be divided into three main groups: air passive cooling, water passive cooling, and conductive cooling. Conductive cooling mostly ends with passive cooling of air, but an important difference is that the prevailing heat transfer mechanism of PV cells is conductive. worked on experimental studies on polycrystalline PV cells under controlled conditions $35.5^{\circ} \mathrm{C}[6]$.

Two PV cells are used: one with aluminum fins as a heat sink, with thermal grease applied and one without a heat sink. Lighting intensity varies from 200 to 800 $\mathrm{W} / \mathrm{m}^{2}$. A relative increase in electrical efficiency of $9 \%$ has been obtained through the use of passive cooling with coolant. have shown that the depth of the flow channel under the PV cell has a significant effect on passive cooling, for a larger PV surface $\left(1.95 \mathrm{~m}^{2}\right)$. It has been shown that, for a length-to-depth ratio of 0.085 , the PV module heats up $5-6^{\circ} \mathrm{C}$ when compared to the PV module in a normal installation. It was noted that the temperature difference increases with increasing insulation. In other words, passive flow channels can have the opposite effect on cooling the PV module [7].

Water passive cooling is somewhat more efficient, mainly because of the higher thermal capacity of water. Several studies have been made with front and back cooling. used a submerged technique to cool down the mono-crystalline PV module in water. The effect had limited success: the temperature was maintained at $30^{\circ} \mathrm{C}$ which in turn yielded a relative efficiency increase of $20 \%$, but insolation intensity dropped with depth. However, at a depth of $4 \mathrm{~cm}$, relative efficiency is increased by $11 \%$ [8].

\section{METHODOLOGY}

This experiment compares 2 monocrystalline solar panels $100 \mathrm{Wp}$, where one solar panel uses a cooling plate, while the other one without a cooling plate. The data to be measured are temperature, voltage, current, and radiation. The halogen lamps totaling 12 pieces used have a capacity of 1000 Watts, mounted on top of the panel with a height of $35 \mathrm{~cm}$ from the solar panel.

Measurements are made using a datalogger, where the datalogger functions to record data using a sensor based on Arduino Mega-2560. The DS18B20 temperature sensor for measuring the temperature is installed on the top and bottom sides of the solar panel so that the temperature comparison between solar panels using cooling plate and without cooling plate is obtained. Furthermore, the resulting voltage is measured using the ZMPT101B Voltage Sensor and the current generated using the Current Sensor ACS712. So that the voltage and current on the solar panel using cooling plate and without cooling plate can be analyzed for comparison. All data measured using the sensor will be recorded by the datalogger and automatically stored on the Micro SD Card.

Datalogger Based on Arduino Mega 2560 can be seen in Figure 1.

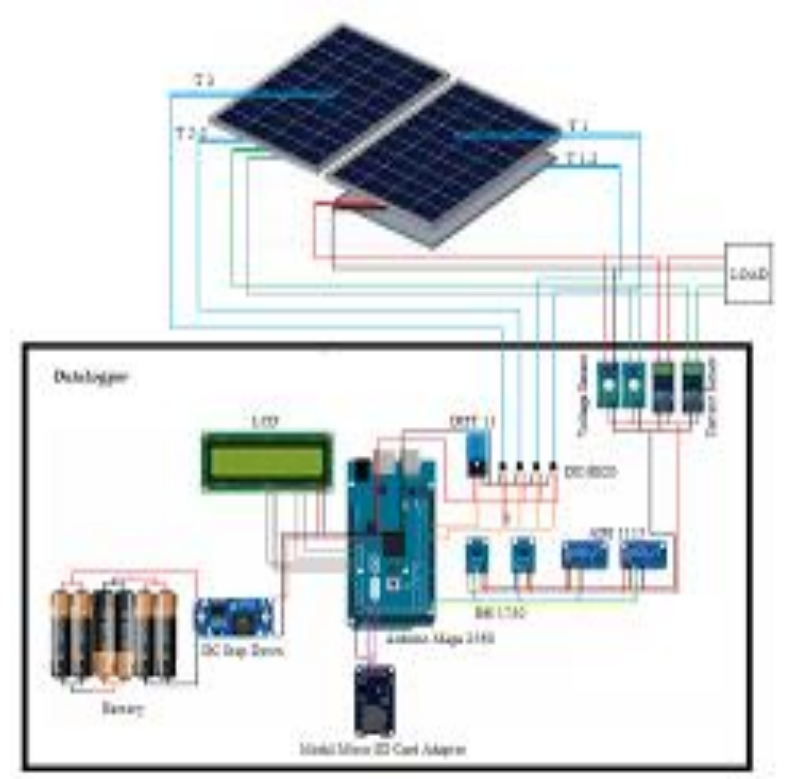

Figure 1 Datalogger Wiring Scheme

\subsection{Research Block Diagram}

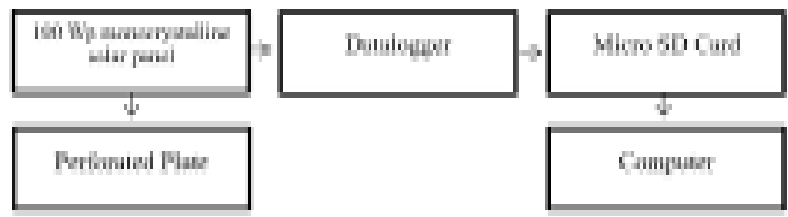

Figure 2 Research Block Diagram

A perforated plate is applied to the bottom of the 100 WP monocrystalline solar panel. The increase in the trigger is used so that the heat in the solar panel does not overheat and can increase the voltage, current, and output power of the solar panel. Measurements are made 
using a datalogger by measuring the resulting voltage and current then calculating the power from the output of the solar panels. The datalogger is also used to measure the intensity of the sun and also the temperature on the solar panels.

\subsection{PV Panel}

Two units of monocrystalline photovoltaic panels with a capacity of $100 \mathrm{wp}$ for 2 units, mounted parallel to the panel rack, one of which is installed perforated aluminum plate on the back

The specifications of the PV panels are explained in Table 1.

Table 1. The specifications of the PV panels

\begin{tabular}{|l|l|}
\hline Electric Rating & Specification \\
\hline Max. Power (Pmax) & $100 \mathrm{Wp}$ \\
\hline Optimum Operating Voltage (Vmp) & $18.10 \mathrm{~V}$ \\
\hline Optimum Operating Current (Imp) & $05.52 \mathrm{~A}$ \\
\hline Open-circuit Voltage (Voc) & $22.10 \mathrm{~V}$ \\
\hline Short-circuit Current (Isc) & $05.85 \mathrm{~A}$ \\
\hline Power Tolerance (Pmax) & $0 \sim+3 \%$ \\
\hline Modul Dimension (mm) & $1000 \times 670 \times 30$ \\
\hline Wieght & $8 \mathrm{~kg}$ \\
\hline Max. Series Fuse Rating & $10 \mathrm{~A}$ \\
\hline
\end{tabular}

\subsection{Cooling Media}

Cooling media using perforated aluminum plates described in Table 2 and Figure 3.

Table 2. Dimensions of aluminum perforated plates

\begin{tabular}{|l|l|}
\hline Name of Parts & Specification \\
\hline Dimension & $1000 \times 670 \times 30 \mathrm{~mm}$ \\
\hline Hole Diameter & $2.5 \mathrm{~mm}$ \\
\hline Distance Between Holes & $20 \mathrm{~mm}$ \\
\hline Number of Holes & 1551 \\
\hline Arrangement of Holes & In Line \\
\hline
\end{tabular}

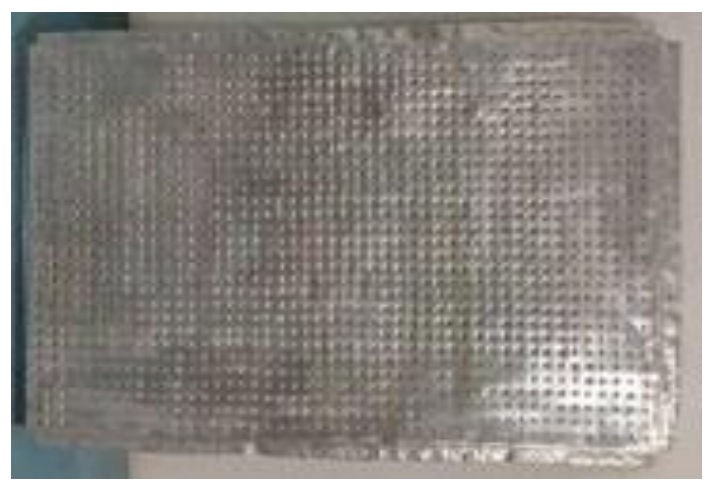

Figure 3 Perforated Aluminium Plate

\section{RESULTS AND DISCUSSION}

Results show the comparison of PV panel temperatures show in Figure 4. The upper (T1) and lower (T1-2) surface temperatures of the solar panel using a perforated plate showed $42.88^{\circ} \mathrm{C}$ and $35.50^{\circ} \mathrm{C}$ respectively at 12:15:05 pm. Meanwhile, the upper (T2) and lower (T2-2) surface temperatures of the solar panel without perforated plates showed $65.00^{\circ} \mathrm{C}$ and $52.94^{\circ} \mathrm{C}$ respectively at 12:15:05 $\mathrm{pm}$.

The body text starts with a standard first-level heading like INTRODUCTION or any other heading suitable to the content and context. First level headings are in all caps. Copy the content and replace it for other first-level headings in remaining text. Reference citations should be within square bracket [1]. Headings should always be followed by text.

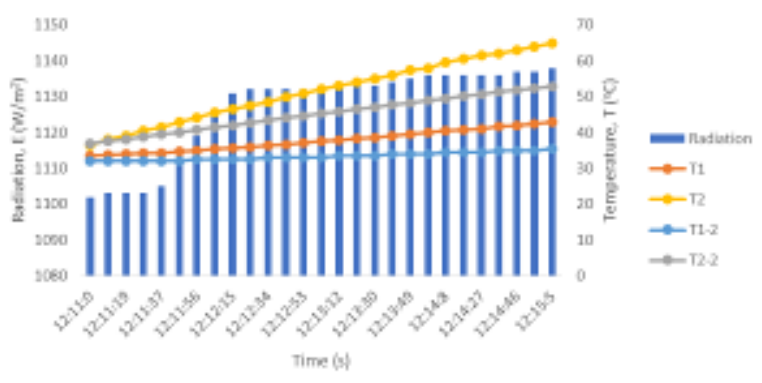

Figure 4 Comparison between upper and under surface temperatures (T1 and T1-2) of PV panel using perforated plate and upper and under surface temperatures (T2 and T2-2) of PV panel without perforated plate
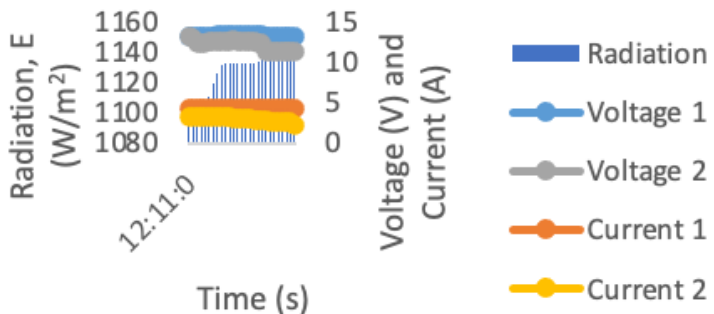

Figure 5 Comparison between (Voltage 1 and Current 1) of PV panel using perforated plate and (Voltage 2 and Current 2) of PV panel without perforated plate

Figure 5 shows the increase in voltage and current, where the highest Voltage 1, Voltage 2, Current 1 and Current 2 are $13.25 \mathrm{~V}, 13.11 \mathrm{~V}, 4.36 \mathrm{~A}$, and $3.34 \mathrm{~A}$, respectively.

Figure 6 shows the highest Power 1 of $57.77 \mathrm{~W}$, and the highest Power 2 of $43.78 \mathrm{~W}$. 


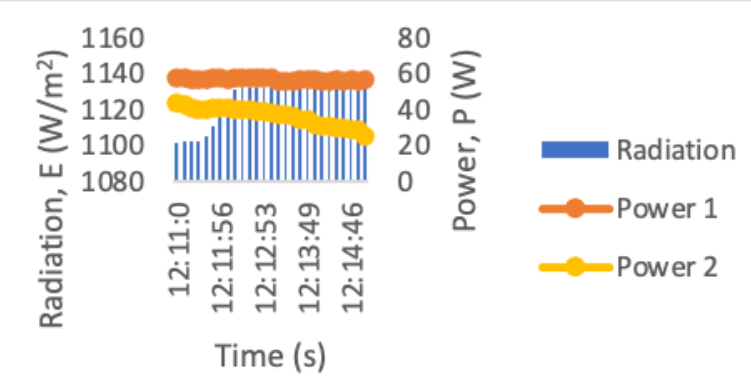

Figure 6 Comparison between (Power 1) of PV panel using perforated plate and (Power 2) of PV panel without perforated plate

\section{CONCLUSION}

PV panels equipped with passive cooling method using perforated aluminum plate with hole diameters of $2.5 \mathrm{~mm}$ can increase voltage by $8.87 \%$ compared to PV panels without perforated aluminium plate.

In addition, PV panels equipped with perforated aluminum plate can reduce the temperature of the under panel by $26.07 \%$ compared to PV panels without perforated aluminum plate.

Also, this experimental research shows the increase on current and output power of PV panels equipped with perforated aluminum plate by $43.87 \%$ and $56.00 \%$, repectively, compared to $\mathrm{PV}$ panels without perforated aluminium plate.

\section{REFERENCES}

[1] G. N. Tiwari and S. Dubey, Fundamentals Of Photovoltaic Modules And Their Application. Cambridge: The Royal Society of Chemistry, 2010.

[2] D. M. Chapin, C. S. Fuller, and G. L. Pearson, "A New Silicon p-n Junction Photocell for Converting Solar Radiation into Electrical Power," vol. 676, no. 1954 , pp. 22-24, 2008.

[3] A. Sofijan, Z. Nawawi, B. Y. Suprapto, R. Sipahutar, and I. Bizzy, "Performance Evaluation Solar Charge Controller on Solar Power System Home-Based SPV Amorphous 80 Watt-peak .," 2020.

[4] M. Badache, D. Rousse, and S. Hallé, "Experimental and two-dimensional numerical simulation of an unglazed transpired solar air collector," vol. 30, pp. 19-28, 2012.

[5] C. F. Kutscher, C. B. Christensen, and G. M. Barker, "Unglazed Transpired Solar Collectors : Heat Loss Theory," vol. 115, no. AUGUST 1993, 2017.

[6] T. L. Bergman, A. S. Lavine, F. P. Incropera, and D. P. Dewitt, Fundamentals Of Heat And Mass Transfer Seventh Edition. United States of America: John Wiley \& Sons, 2011.

[7] I. Ahmed, "Enhancement the Performance of PV Panel by Using Fins as Heat Sink," Eng. Technol. J., vol. 36, no. 7A, 2018.

[8] G. Mooko and K. Kusakana, "Prospective use of thermoelectric device for PV panel cooling," 2018 Open Innov. Conf., pp. 68-72, 2018. 